the sense of frustration which might arise out of delay in dealing with representations in such circumstances, and Dr. Keen is convinced that the rightful sphere for planning and organization is in the technological stage. Even so, the plan should in general be prepared by a local body, familiar with the problems and priorities and local conditions. In fundamental research, organization and planning, except in the very broadest general terms, are, in his opinion, useless. "Research," as the late Sir Daniel Hall said as long ago as 1927 to the Imperial Agricultural Research Conference, "is after all a product of the individual. It is a matter of imagination and intuition ... and no administrator, no organization, can of itself turn it out."

\section{HIGH-POLYMER CHEMISTRY}

Physical Chemistry of High Polymeric Systems By H. Mark and A. V. Tobolsky. (High Polymers, Vol. 2.) Pp. $\mathrm{xi}+506$. 52s.

Natural and Synthetic High Polymers

A Textbook and Reference Book for Chemists and Biologists. By Prof. Kurt H. Meyer. (High Polymers, Vol. 4.) Pp. Xx +891 . $120 s$.

Second completely revised and augmented editions. (New York and London : Interscience Publishers, Inc., 1950.)

$\mathrm{T}$ HESE two volumes are second editions of volumes dealing with important aspects of highpolymer chemistry. Both were first published nearly ten years ago, and it is therefore interesting to see what progress has occurred in a period of considerable activity in this field of chemistry. In spite of very striking advances, the pattern of these books has remained essentially unchanged. This reflects the farsightedness of the authors in mapping out the most likely fields in which further advances were likely to occur. Fortunately, the authors have contrived to incorporate the new knowledge without too large an increase in the size of either volume.

The first work, Vol. 2 of the series, is really more a book on physical chemistry required for the understanding of high-polymer chemistry than a book on high-polymer chemistry itself. In preparing this new edition Prof. H. Mark has had the collaboration of Dr. A. V. Tobolsky. It includes a great deal of molecular structure, thermodynamics and kinetics treated in a rather unusual and therefore useful way, which should be of considerable interest to those readers not specially interested in high polymers. In the sections on structures a large amount of new material has accumulated. The important new developments are skilfully blended with the principles of the subject. The main emphasis is still on the basic principles, because one object of this volume is to provide a rational description of these principles so that the other volumes can be all the more readily understood and appreciated. Similarly, in the section on the behaviour of high-polymer solutions, much clarification in this field has been achieved, although the basic pattern remains. The largest now section is that dealing with the kinetics. Here a minor revolution has occurred, and the whole subject has become quantitative and exact, and therefore takes its place along with thermodynamical treatments of high-polymer solutions in a much improved form and perspective. A completely new chapter on the degradation of high polymers has been added.

In the second book, Vol, 4 of the series, by Prof. K. H. Meyer, the object is rather different. Natural and synthetic high polymers, with the main emphasis on structure, are dealt with in an individualistic way which is to be expected. There is, naturally, some overlap of subject with other volumes of the series; but the authors' points of view are usually so different that nothing is lost by looking at high-polymer chemistry-especially the more controversial fields-in a number of ways. In this volume, too, the pattern is unchanged; but at every point there is included new knowledge of the past decade. There is, naturally, a much extended section on rubbers, and the section on polysaccharides is thoroughly revised and to some extent rearranged. Due notice is taken of the new knowledge in starch chemistry and other fields of polysaccharide chemistry. In the section on protein chemistry all the major advances are recorded, and there is a good deal of rearrangement. Dr. A. J. A. van der Wyk has collaborated with Prof. Meyer in revising a much-extended section on high-polymer solutions and the mechanical properties of highpolymer substances. All this new treatment has been incorporated by the addition of only two hundred pages to the volume, which is the minimum that could probably be achieved.

The printing and binding of both the books are up to the high standard expected in this series. Unfortunately, the expansion has resulted in an increase in price.

H. W. Melville

\section{PLANT PROPAGATION FOR THE HORTICULTURIST}

The Propagation of Plants

By E. J. King. Pp. 264. (London: Hutchinson's Scientific and Technical Publications, n.d.) 16s. net.

$\mathrm{N}$ this book the author has condensed into a small compass a vast amount of information concerning the propagation of plants. Information which is widely scattered in scientific monographs, botanical text-books, commorcial handbooks and similar publications has been brought together by the author. He has simplified this mass of detail, integrated it with knowledge gained from his own wide practical experience and has presented it in a concise, readable form easily understood by the intelligent amateur gardener. But the book does not consist merely of a description of rule-of-thumb methods of propagation ; the botanical principles underlying the art and science of propagation are also clearly explained.

The contents are divided into two parts, the first dealing with "Propagation by Seeds", and the second, and much larger, section with "Vegetative Propagation". The former section covers a wide range of subjects, from the preparation of the seed-bed to the harvesting of home-saved seed; and, in the chapters devoted to vegetative propagation, all the standard methods used by horticulturists are described and, in some cases, illustrated by line drawings.

The author also discusses briefly the newer methods of propagation involving the use of plant hormones, but he has omitted to include other modern methods now in general practice; for example, in the section dealing with the raising of orchids from seed, there is no mention of non-symbiotic germination. The com- 